\title{
Polymorphisms of glutathione S-transferase Mu 1 (GSTM1), Theta 1 (GSTT1), and Pi 1 (GSTP1) genes and epithelial ovarian cancer risk
}

\author{
Cristiane Oliveira $^{\mathrm{a}}$, Gustavo Jacob Lourenço ${ }^{\mathrm{a}}$, Regina Aparecida Martinho Sagarra ${ }^{\mathrm{a}}$, \\ Sophie Françoise Mauricette Derchain ${ }^{\mathrm{b}}$, José Getulio Segalla ${ }^{\mathrm{c}}$ and Carmen Silvia Passos Limaa,* \\ ${ }^{a}$ Clinical Oncology Service, Department of Internal Medicine, Faculty of Medical Sciences, State University of \\ Campinas, Campinas, São Paulo, Brazil \\ ${ }^{\mathrm{b}}$ Department of Obstetrics and Gynecology, Faculty of Medical Sciences, State University of Campinas, Campinas, \\ São Paulo, Brazil \\ c Amaral Carvalho Hospital, Jaú, São Paulo, Brazil
}

\begin{abstract}
Background: Exposure of ovarian cells to estrogen, which is detoxified by glutathione S-transferases (GSTs), has been associated with epithelial ovarian cancer (EOC) development.

Objectives: We tested in this study whether the GSTM1, GSTT1 and GSTP1 Ile105Val polymorphisms alter the risk of EOC.

Materials and methods: Genomic DNA from 132 EOC patients and 132 controls was analyzed by polymerase chain reaction and restriction fragment length polymorphism methods. The differences between groups were analyzed by $\chi^{2}$ or Fisher's exact test. Results: The frequencies of GSTP1 Ile/Ile (57.6\% versus $45.5 \%, P=0.03)$, GSTM1 null plus GSTP1 Ile/Ile (43.5\% versus $25.8 \% ; P=0.03)$ and GSTM1 null plus GSTT1 null plus GSTP1 Ile/Ile (30.3\% versus $7.7 \% ; P=0.007)$ genotypes were higher in patients than in controls. Individuals with the respective genotypes had a 1.80 (95\% CI: 1.06-3.06), 2.38 (95\% CI: 1.08-5.24) and 11.28 (95 \%CI: 1.95-65.30)-fold increased risks of EOC than those with the remaining genotypes.

Conclusions: Our data present preliminary evidence that GSTM1, GSTT1 and GSTP1 polymorphisms, particularly in combination, constitute important inherited EOC determinants in individuals from Southeastern Brazil.
\end{abstract}

Keywords: Epithelial ovarian cancer, risk, GSTM1, GSTT1, GSTP1

\section{Introduction}

Estrogen and its metabolites act as initiators of genetic damage in ovarian cells by reactive oxygen species (ROS) [1] and are involved in epithelial ovarian cancer (EOC) development.

\footnotetext{
*Corresponding author: Carmen S. P. Lima, MD, PhD, Clinical Oncology Service, Department of Internal Medicine, Rua Alexander Fleming 181, Cidade Universitária "Zeferino Vaz", Distrito de Barão Geraldo, Campinas, São Paulo, Brazil. CEP: 13083-970, Tel./Fax: +55 193521 7496; E-mail: carmenl@fcm.unicamp.br.
}

The detoxification of estrogen and ROS is performed by glutathione S-transferases M1, T1 and P1 [2]. GSTM1, GSTT1 and GSTP1 genes are polymorphic in humans. Genes are homozygous deleted in approximately 50\% (GSTM1) and 20\% (GSTT1) of Caucasians, resulting in loss of enzymatic activity [2]. Val/Val genotype of GSTP1 Ile105Val polymorphism is identified in $0-15 \%$ of healthy individuals [3], and the protein encoded by Val allele has a defective enzymatic activity in protecting cells from oxidative damage [4].

The absence or reduction of M1, T1 and P1 enzymes has been associated with malignant transforma- 
tion of mammary and ovarian cells [5,6], but the roles of GSTM1, GSTT1 and GSTP1 Ile105Val polymorphisms, isolated or in combination, for the risk of EOC in Caucasians are still unclear [7-15].

The Brazilian population is highly heterogeneous, consisting of Amerindians and immigrants from Europe, Africa and Asia [16]. Thus, the identification of genotypes of aforementioned polymorphisms in healthy and EOC women was considered necessary to test their influences on the disease in our country.

\section{Materials and methods}

The case group comprised 132 consecutive EOC patients at diagnosis (median age: 53 years, range: $21-$ 91; 126 Caucasians, 6 non-Caucasians: 58 with serous tumors and 74 with non-serous tumors) seen at the University Hospital and Amaral Carvalho Hospital from June 2007 to May 2010. The EOC was diagnosed according to the criteria of the World Health Organization [17]. One-hundred thirty-two female blood donors (median age: 50 years, range: 39-62; 126 Caucasians, 6 non-Caucasians), seen at the same Institution and period of study, served as controls to provide a representative group of the general population that seeks medical assistance in this region. Selection criteria for individuals were no evidence of any personal or family history of ovarian cancer. All procedures were carried out according to the Helsinki Declaration and written informed consent was obtained from each study participant.

Genomic DNA from peripheral blood of individuals was analyzed by polymerase chain reaction (PCR) multiplex for GSTM1 and GSTT1 [18] and PCR followed by enzymatic digestion for GSTP1 Ile105Val (rs1695) genotyping [19].

The Hardy-Weinberg (HW) equilibrium was evaluated using the chi-square $\left(\chi^{2}\right)$ goodness of fit test. The differences between groups were analyzed by the $\chi^{2}$ or Fisher's exact test. The statistical significance of the differences between median values of the groups was calculated by Mann-Whitney test. Multivariate analysis was performed using the logistic regression model and served to obtain age-adjusted odds ratio (ORs) and assess the associations between genotypes and EOC. Power analysis (PA) was used to calculate the minimum effect size that is likely to be detected in a study using a given sample size (DSS research Statistical Power Calculators: http://www.dssresearch.com/Knowledge Center/toolkitcalculators/statisticalpowercalculators. aspx). Statistical significance was established at a $P<$
Table 1

Clinical aspects of patients with epithelial ovarian cancer and controls and tumor characteristics of patients

\begin{tabular}{|c|c|c|c|}
\hline Clinical aspect & Patients (\%) & Controls (\%) & $P$ value \\
\hline \multirow{2}{*}{$\begin{array}{l}\text { Median age (years) } \\
\text { range }\end{array}$} & 53.5 & 49.8 & 0.003 \\
\hline & 21-91 years & $39-62$ years & \\
\hline \multicolumn{4}{|l|}{ Ethnical origin } \\
\hline Caucasian & $126(95.4)$ & $126(95.4)$ & 1.00 \\
\hline Black & $6(4.6)$ & $6(4.6)$ & \\
\hline \multicolumn{4}{|l|}{ Tumor characteristic } \\
\hline Serous & $58(43.9)$ & & \\
\hline Endometrioid & $22(16.7)$ & & \\
\hline Mucinous & $18(13.6)$ & & \\
\hline Undifferentiated & $15(11.3)$ & & \\
\hline Clear cell & $8(6.1)$ & & \\
\hline Mixed & $7(5.3)$ & & \\
\hline Transitional & $3(2.3)$ & & \\
\hline Epidermóide & $1(0.8)$ & & \\
\hline \multicolumn{4}{|l|}{ Histologic grade } \\
\hline I & $45(34.1)$ & & \\
\hline II & $52(39.4)$ & & \\
\hline III & $35(26.5)$ & & \\
\hline \multicolumn{4}{|l|}{ Stage of tumor } \\
\hline I & $52(39.4)$ & & \\
\hline II & $13(9.8)$ & & \\
\hline III & $58(44.0)$ & & \\
\hline IV & $9(6.8)$ & & \\
\hline
\end{tabular}

0.05 and testes were done using the SPSS 15.0 software (SPSS Incorporation, Chicago, IL, USA).

\section{Results}

The clinical aspects of participants and tumor characteristics are presented in Table 1 . Differences in age of patients and controls were corrected in all statistical analyses.

Controls' samples were under HW equilibrium ( $\chi^{2}=0.07, P=0.79$ ) but patients' samples did not confirm the HW expectation at the GSTP1 Ile105Val locus $\left(\chi^{2}=4.44, P=0.03\right)$.

Similar frequencies of isolated and combined GSTM1 and GSTT1 genotypes were seen in patients and controls. Individuals with distinct genotypes were under similar risks for the disease. In contrast, GSTP1 Ile/Ile genotype was more common in patients than in controls (57.6\% versus $45.5 \%$ ). Carriers of the genotype were under a 1.80 (95\% CI: 1.06-3.06)-fold increased risk for EOC than those with Ile/Val and Val/Val genotypes (power of analysis: $34 \%$ ). Excesses of GSTM1 null plus GSTP1 Ile/Ile (43.5\% versus $25.8 \%$ ) and GSTM1 null plus GSTT1 null plus GSTP1 Ile/Ile (30.3\% versus $7.7 \%$ ) combined genotypes were also more seen in patients than in controls. Individuals with the respective genotypes had a 2.38 (95\% CI: 1.08-5.24)-fold (power 
Table 2

GSTs genotypes in patients with epithelial ovarian cancer and controls

\begin{tabular}{|c|c|c|c|c|c|}
\hline \multirow[t]{2}{*}{ Genotypes } & \multicolumn{2}{|c|}{ Number (\%) } & \multirow[t]{2}{*}{$P$-value } & \multirow[t]{2}{*}{$\mathrm{OR}^{*}(95 \% \mathrm{CI})$} & \multirow[t]{2}{*}{ Power analysis } \\
\hline & Patients & Controls & & & \\
\hline \multicolumn{6}{|l|}{$\overline{G S T M 1}$} \\
\hline Null & $48(36.4)$ & $42(31.8)$ & 0.42 & $1.23(0.73-2.07)$ & $12 \%$ \\
\hline Present & $84(63.6)$ & $90(68.2)$ & & 1.00 (reference) & \\
\hline \multicolumn{6}{|l|}{ GSTT1 } \\
\hline Null & $39(29.5)$ & $34(25.7)$ & 0.47 & $1.22(0.70-2.12)$ & $11 \%$ \\
\hline Present & $93(70.5)$ & $98(74.3)$ & & 1.00 (reference) & \\
\hline \multicolumn{6}{|l|}{ GSTM1/GSTT1 } \\
\hline One null & $72(54.5)$ & $68(51.5)$ & 0.71 & $1.09(0.66-1.79)$ & $8 \%$ \\
\hline Both null & $15(11.4)$ & $8(6.0)$ & 0.08 & $2.35(0.90-6.16)$ & $21 \%$ \\
\hline Both present & $60(45.5)$ & $64(48.5)$ & & 1.00 (reference) & \\
\hline \multicolumn{6}{|l|}{ GSTP1 } \\
\hline Ile/Ile & $76(57.6)$ & $60(45.5)$ & 0.03 & $1.80(1.06-3.06)$ & $34 \%$ \\
\hline Ile/Val & $42(31.8)$ & $59(44.7)$ & 0.62 & $1.23(0.53-2.87)$ & $32 \%$ \\
\hline $\mathrm{Val} / \mathrm{Val}$ & $14(10.6)$ & $13(9.8)$ & & 1.00 (reference) & \\
\hline Ile/Ile+Ile/Val & $118(89.4)$ & $119(90.2)$ & 0.89 & $1.23(0.53-2.87)$ & $6 \%$ \\
\hline $\mathrm{Val} / \mathrm{Val}$ & $14(10.6)$ & $13(9.8)$ & & 1.00 (reference) & \\
\hline Ile/Ile & $76(57.6)$ & $60(45.5)$ & 0.04 & $1.68(1.02-2.77)$ & $51 \%$ \\
\hline $\mathrm{Ile} / \mathrm{Val}+\mathrm{Val} / \mathrm{Val}$ & $56(42.4)$ & $72(54.5)$ & & 1.00 (reference) & \\
\hline \multicolumn{6}{|l|}{ GSTM1/GSTP1 } \\
\hline Null + Ile/Ile+Ile/Val & $42(84.0)$ & $37(82.2)$ & 0.80 & $1.14(0.39-3.37)$ & $6 \%$ \\
\hline Present + Val/Val & $8(16.0)$ & $8(17.8)$ & & 1.00 (reference) & \\
\hline Null + Ile/Ile & $27(43.5)$ & $16(25.8)$ & 0.03 & $2.38(1.08-5.24)$ & $55 \%$ \\
\hline Present + Ile/Val+Val/Val & $35(56.5)$ & $46(74.2)$ & & 1.00 (reference) & \\
\hline \multicolumn{6}{|l|}{ GSTT1/GSTP1 } \\
\hline Null + Ile/Ile+Ile/Val & $34(79.0)$ & $28(80.0)$ & 0.98 & $1.01(0.31-3.22)$ & $5 \%$ \\
\hline Present + Val/Val & $9(21.0)$ & $7(20.0)$ & & 1.00 (reference) & \\
\hline Null + Ile/Ile & $22(36.0)$ & $19(25.0)$ & 0.12 & $1.81(0.85-3.87)$ & $29 \%$ \\
\hline Present + Ile/Val+Val/Val & $39(64.0)$ & $57(75.0)$ & & 1.00 (reference) & \\
\hline \multicolumn{6}{|l|}{ GSTM1/GSTT1/GSTP1 } \\
\hline Null + Null + Ile/Ile+Ile/Val & $13(72.2)$ & $6(60.0)$ & 0.32 & $2.37(0.42-13.36)$ & $11 \%$ \\
\hline Present + Present + Val/Val & $5(27.8)$ & $4(40.0)$ & & 1.00 (reference) & \\
\hline Null + Null + Ile/Ile & $10(30.3)$ & $3(7.7)$ & 0.007 & $11.28(1.95-65.30)$ & $70 \%$ \\
\hline Present + Present $+\mathrm{Ile} / \mathrm{Val}+\mathrm{Val} / \mathrm{Val}$ & $23(69.7)$ & $36(92.3)$ & & 1.00 (reference) & \\
\hline
\end{tabular}

*age-adjusted odds ratio; CI: confidence interval.

of analysis: $55 \%$ ) and 11.28-fold (95\% CI: 1.95-65.30) (power of analysis: $70 \%$ ) increased risks for EOC than those with the remaining genotypes (Table 2).

Similar frequencies of isolated and combined GSTM1, GSTT1 and GSTP1 genotypes were seen in patients stratified by age, ethnical origin, histological subtypes, grade and stage of the tumor (data not shown).

\section{Discussion}

We have investigated the influence of GSTM1, GSTT1, and GSTP1 Ile105Val polymorphisms on susceptibility and tumor characteristics of EOC in a casecontrol study conducted in Southeastern Brazil.

We initially observed similar frequencies of GSTM1 and GSTT1 genotypes in patients and controls, as previously seen in England [7], Germany [8], United States [9], Australia [11], Brazil [12] and France [13].
Baxter et al. [10] found an excess of GSTM1 null genotype in Caucasian EOC patients when compared with controls from England. Association of GSTT1 null genotype with EOC was also seen only in a particular women group with genital talc use by Gates et al. [13]. Our results, as well as those of a recent meta-analysis of previous studies conducted by Economopoulos et al. [15], advocated that GSTM1 and GSTT1 genotypes do not confer additional risk for EOC.

Secondly, we observed that GSTPI Ile/Ile wild genotype was associated with an increased risk of EOC (power of analysis: 34\%), in disaccord with studies conducted in Australia [11] and France [14]. No influence of GSTP1 Ile105Val polymorphism for the EOC risk in Caucasians was also seen in a recent metaanalysis [15]. In fact, the association between GSTP1 Ile/Ile genotype and increased risk of EOC in our cases was unexpected because the protein encoded by wild Ile allele seems to be more efficient in protecting cells 
from oxidative damage than that produced by variant Val allele [4]. Otherwise, Holley et al. [20] demonstrated that the wild and variant alleles of the GSTP1 Ile105Val polymorphism protect cells against apoptosis through JNK-independent and JNK-mediated mechanisms, respectively. Thus, the association of GSTP1 wild genotype and EOC increased risk in our study might be attributed to the effects of the protein encoded by Ile allele for favoring ovarian cell survival by a JNK-independent mechanism.

Thirdly, we observed associations between GSTM1 null plus GSTP1 Ile/Ile and GSTM1/GSTT1 null plus GSTP1 Ile/Ile with increased risk of EOC (power of analysis $55 \%$ and $70 \%$ respectively). According to Gates et al. [13], associations of GSTT1 null and combined GSTM1/GSTT1 null genotypes with EOC were seen in women using talc in their genital. In contrast, Spurdle et al. [11] and Morari et al. [12] found no association of combined GSTM1/GSTT1 null genotypes with EOC risk. Thus, we reported for the first time that GSTM1 null, GSTT1 null and GSTP1 Ile/Ile genotypes in combination increase consistently the disease risk in our population, suggesting that GSTs can act synergistically in EOC development. In fact, GSTM1, GSTT1, and GSTPI act on estrogen and ROS metabolism involved in EOC [1,4-6], and inherited homozygous deletions or mutation of the genes lead to the complete absence or reduced activity of enzymes $[2,4]$ and possibly to malignant transformation of ovarian cells [5].

Finally, we observed no associations of GSTM1, GSTT1 and GSTP1 genotypes with age, ethnical origin, histological type, tumor grade and stage in this study, as previously reported [8,15]. Endometrioid/clear cell subtypes had an increased frequency of GSTM1 null, according to Baxter's [10] and Spurdle's (2001) [11] studies, suggesting that EOC of different histological types may have different etiologies [21].

The data present preliminary evidence that GSTM1, GSTT1, and GSTP1, particularly in combination, alter the risk of EOC in a mixed population from Southeastern Brazil. We recognize that our conclusions are based on relatively small numbers of individuals and will require verification from additional larger independent studies. Moreover, functional analyses of the proteins encoded by the wild and variant alleles of GSTP1 gene on ovarian cell survival are also required for clarifying the roles of the gene in EOC development.

\section{Acknowledgments}

This study was supported by Fundação de Amparo à Pesquisa do Estado de São Paulo (FAPESP) and Con- selho Nacional de Desenvolvimento Científico e Tecnológico (CNPq).

\section{References}

[1] D. Roy, Q. Cai, Q. Felty and S. Narayan, Estrogen-induced generation of reactive oxygen and nitrogen species, gene damage, and estrogen-dependent cancers, J Toxicol Environ Health B Crit Rev 10(4) (2007), 235-257.

[2] J.D. Hayes, J.U. Flanagan and I.R. Jowsey, Glutathione transferases, Аппи Rev Pharmacol Toxicol 45 (2005), 51-88.

[3] E. Kellen, M. Hemelt, K. Broberg, K. Golka, V.N. Kristensen, R.J. Hung, G. Matullo, R.D. Mittal, S. Porru, A. Povey, W.A. Schulz, J. Shen, F. Buntinx, M.P. Zeegers and E. Taioli, Pooled analysis and meta-analysis of the glutathione S-transferase P1 Ile105Val polymorphism and bladder cancer: a HuGE-GSEC review, Am J Epidemiol 65 (2007), 1221-1230.

[4] C.J. Henderson, A.W. McLaren, G.J. Moffat, E.J. Bacon and C.R. Wolf, Pi-class glutathione S-transferase: regulation and function, Chem Biol Interact 24(111-112) (1998), 69-82.

[5] J.G. Bisseling, M.F. Knapen, H.J. Goverde, T.P. Mulder, W.H. Peters, W.N. Willemsen C.M. Thomas and E.A. Steegers, Glutathione S-transferases in human ovarian follicular fluid Fertil Steril 68(5) (1997), 907-911.

[6] D.L. Hachey S. Dawling, N. Roodi and F.F. Parl, Sequential action of phase I and II enzymes cytochrome p450 1B1 and glutathione S-transferase P1 in mammary estrogen metabolism Cancer Res 63(23) (2003), 8492-8499.

[7] P. Sarhanis, C. Redman, C. Perrett, K. Brannigan, R.N. Clayton, P. Hand, C. Musgrove, V. Suarez, P. Jones, A.A. Fryer, W.E. Farrell and R.C. Strange, Epithelial ovarian cancer: influence of polymorphism at the glutathione S-transferase GSTM1 and GSTT1 loci on p53 expression, Br J Cancer 74(11) (1996), 1757-1761.

[8] J.G. Hengstler, A. Kett, M. Arand, B. Oesch-Bartlomowicz, F. Oesh, H. Pilch and B. Tanner, Glutathione S-transferase T1 and M1 gene defects in ovarian carcinoma, Cancer Lett 130(1-2) (1998), 43-88.

[9] T.A. Lallas, S.K. McClain, M.S. Shahin and R.E. Buller, The Glutathione S-transferase M1 genotype in ovarian cancer, Cancer Epidemiol Biomarkers Prev 9 (2000), 587-590.

[10] S.W. Baxter, E.J. Thomas and I.G. Campbell, GSTM1 null polymorphism and susceptibility to endometriosis and ovarian cancer, Carcinogenesis 22(1) (2001), 63-65.

[11] A.B. Spurdle, P.M. Webb, D.M. Purdie, X. Chen, A. Green and G. Chenevix-Trench, Polymorphisms at the glutathione Stransferase GSTM1, GSTT1 and GSTP1 loci: risk of ovarian cancer by histological subtype, Carcinogenesis 22(1) (2001), 67-72.

[12] E.C. Morari, A.B. Lima, N.E. Bufalo, J.L. Leite, F. Granja and L.S. Ward, Role of glutathione-S-transferase and codon 72 of P53 genotypes in epithelial ovarian cancer patients, $J$ Cancer Res Clin Oncol 132(8) (2006), 521-528.

[13] M.A. Gates, S.S. Tworoger, K.L. Terry, L. Titus-Ernstoff, B. Rosner, I. De Vivo, D.W. Cramer and S.E. Hankinson, Talc use, variants of the GSTM1, GSTT1, and NAT2 genes, and risk of epithelial ovarian cancer, Cancer Epidemiol Biomarkers Prev 17(9) (2008), 2436-2444.

[14] L. Delort, N. Chalabi, S. Satih, N. Rabiau, F. Kwiatkowski, Y.J. Bignon and D.J. Bernard-Gallon, Association between genetic polymorphisms and ovarian cancer risk, Anticancer Res 5B (2008), 3079-3081. 
[15] K.P. Economopoulos, T.N. Sergentanis and N.F. Vlahos, Glutathione S-transferase M1, T1, and P1 polymorphisms and ovarian cancer risk: A meta-analysis, Int J Gynecol Cancer 20(5) (2010), 732-737.

[16] S.D. Pena, G. Di Pietro, M. Fuchshuber-Moraes, J.P. Genro, M.H. Hutz, S. Kehdy Fde, F. Kohlrausch, L.A. Magno, R.C. Montenegro, M.O. Moraes, M.E. de Moraes, M.R. de Moraes, E.B. Ojopi, J.A. Perini, C. Racciopi, A.K. RibeiroDos-Santos, F. Rios-Santos, M.A. Romano-Silva, V.A. Sortica and G. Suarez-Kurtz, The genomic ancestry of individulals from different geographical regions of Brazil is more uniform than expected, Plos One 6(2) (2011), 17063.

[17] World Health Organization: Tumors of the breast and female genital organs. Lyon: International Agency for Research in Cancer (2003).

[18] V.R. Arruda, C.S.P. Lima, C.R.E. Grignoli, M.B. de Melo,
I. Lorand-Metze, F.L. Alberto, S.T. Saad and F.F. Costa, Increased risk for acute myeloid leukaemia in individuals with glutathione S-transferase mu 1 (GSTM1) and tetha 1 (GSTT1) gene defects, Eur J Haematol 66 (2001), 383-388.

[19] S. Hohaus, A. Di Ruscio, A. Di Febo, G. Massini, F. D’Alo, F. Guidi, G. Mansueto, M.T. Voso and G. Leone, Glutathione S-transferase P1 genotype and prognosis in Hodgkin's lymphoma, Clin Cancer Res 11 (2005), 2175-2179.

[20] S.L. Holley, A.A. Fryer, J.W. Haycock, S.E. Grubb, R.C. Strange and P.R. Hoban, Differential effects of glutathione Stransferase pi (GSTP1) haplotypes on cell proliferation and apoptosis, Carcinogenesis 28 (2007), 2268-2273.

[21] Y. Ichikawa, M. Nishida H. Suzuki, S. Yoshida, H. Tsunoda T. Kubo, K. Uchida and M. Miwa, Mutation of K-ras protooncogene is associated with histological subtypes in human mucinous ovarian tumors, Cancer Res 54(1) (1994), 33-35. 


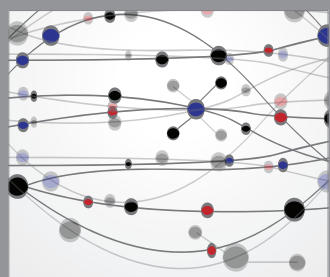

The Scientific World Journal
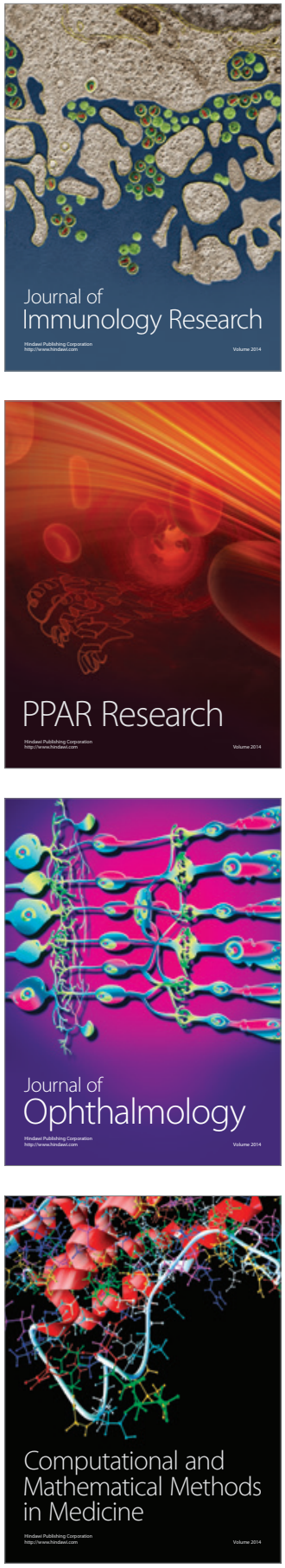

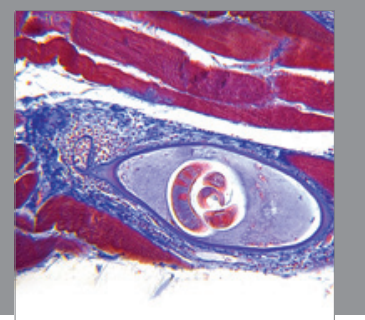

Gastroenterology

Research and Practice
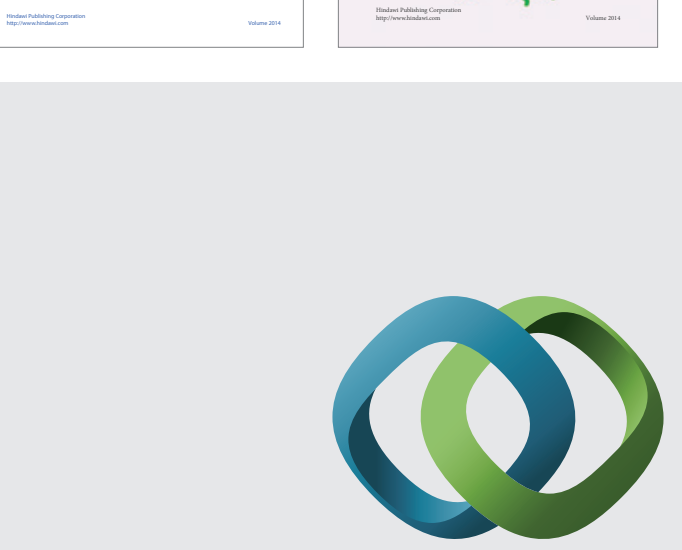

\section{Hindawi}

Submit your manuscripts at

http://www.hindawi.com
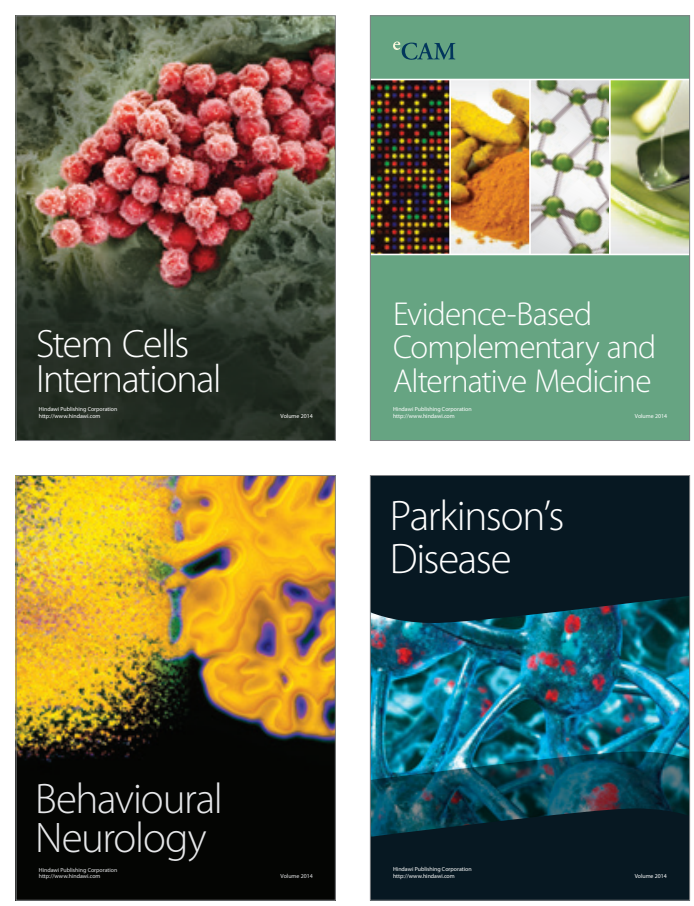

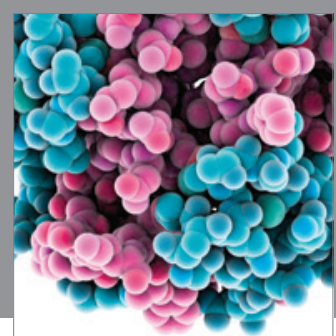

Journal of
Diabetes Research

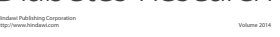

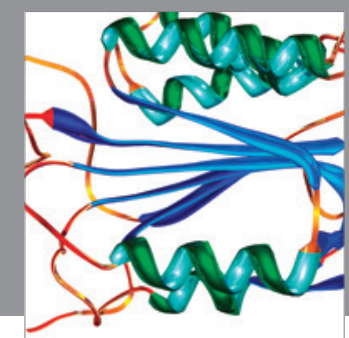

Disease Markers
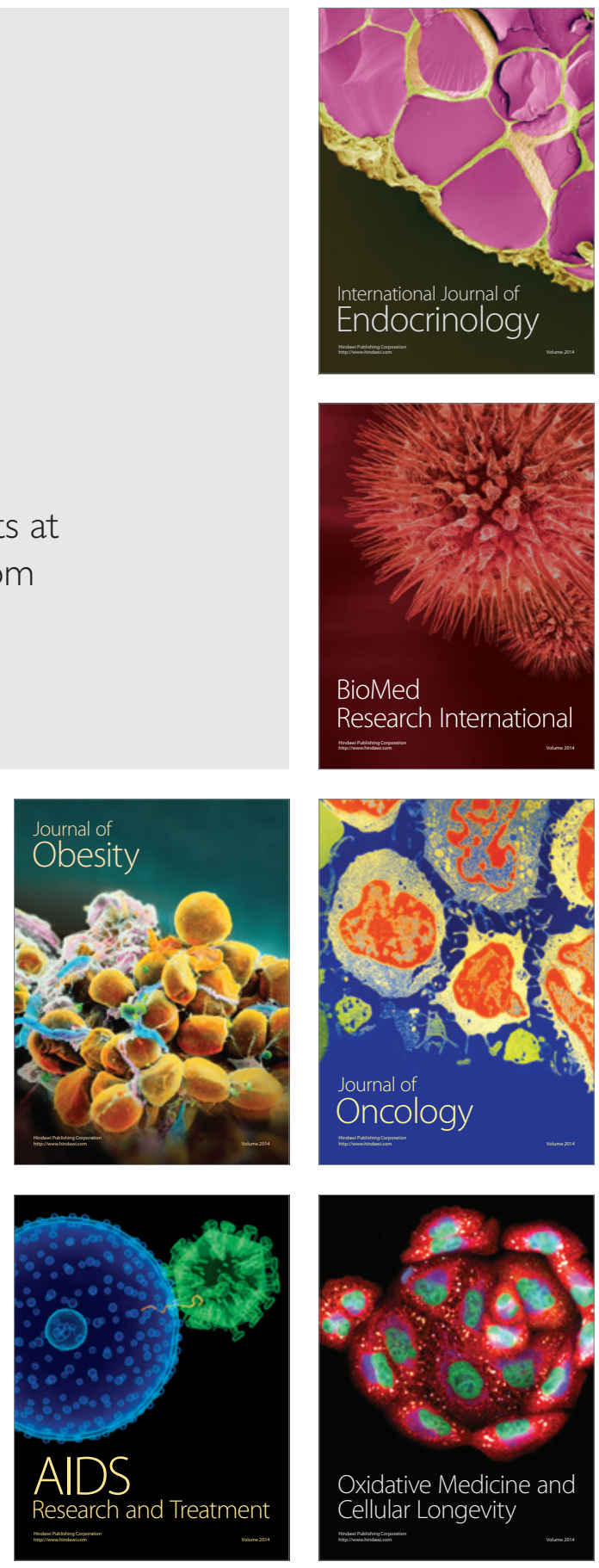